\title{
Peroxisome proliferator-activated receptors: a therapeutic target in COPD?
}

\author{
A.H. Remels*, H.R. Gosker*, P. Schrauwen” , R.C. Langen* and A.M. Schols*
}

ABSTRACT: Extrapulmonary pathology significantly impairs clinical outcome in chronic obstructive pulmonary disease (COPD).

The peroxisome proliferator-activated receptors (PPARs) are implicated in the regulation of several hallmarks of systemic COPD pathology, including cachexia, decreased oxidative muscle metabolism, oxidative stress and systemic inflammation.

Recently, expression of PPARs and related cofactors was shown to be reduced in peripheral skeletal muscle of patients with moderate-to-severe COPD and muscle weakness.

The current authors hypothesise that impaired peroxisome proliferator-activated receptor signalling may underlie some of the muscular disturbances in chronic obstructive pulmonary disease. Proposed mechanisms will be outlined in the present article, as well as the therapeutic potential of peroxisome proliferator-activated receptor modulation in the treatment of skeletal muscle dysfunction.

KEYWORDS: Chronic obstructive pulmonary disease, inflammation, oxidative stress, peroxisome proliferator-activated receptors, skeletal muscle

hronic obstructive pulmonary disease (COPD) is a lung disease characterised by irreversible airway obstruction and an abnormal chronic inflammatory response of the airways. Dominant symptoms are dyspnoea and impaired exercise capacity. These symptoms lead to progressive disability and poor health status, but correlate poorly with severity of local impairment in the lungs. Surprisingly, even in the most recent international guidelines for diagnosis of COPD, staging is still only based on severity of airway obstruction [1]. However, there is increasing evidence in the literature that COPD should not be considered as a localised pulmonary disorder but as a systemic disease involving pathology in several extrapulmonary tissues. Well-characterised systemic features are a chronic low-grade systemic inflammation and altered protein metabolism which, in a subgroup of severe COPD patients, initially results in muscle atrophy only (commonly referred to as sarcopaenia) and in later stages also in cachexia [2, 3]. Muscle atrophy is associated with increased mortality risk independent of disease staging [4]. Besides muscle atrophy, it is well established that intrinsic abnormalities in structure and metabolism are present in the remaining muscle in moderate-to-severe COPD. Muscle atrophy and muscle dysfunction both contribute to reduced strength and endurance of the muscle, which in turn limits exercise capacity. A recent metaanalysis showed that skeletal muscle in patients with moderate-to-severe COPD shows a fibre-type shift from type I oxidative fibres to type II glycolytic fibres [5]. In addition, skeletal muscle in patients is characterised by a reduced oxidative capacity and recently in vitro impaired mitochondrial respiration was even shown in underweight patients with severe COPD [6].

It is still unclear whether the molecular mechanisms of muscular impairment in COPD are governed by disease-specific factors or common denominators of chronic wasting disease. The elucidation of these mechanisms is a crucial step towards developing specific therapies aimed at improving functionality and health status of these patients. Intriguingly, oxidative capacity and fibretype composition of skeletal muscle are controlled or affected by signalling through the nuclear receptor family of peroxisome proliferator-activated receptors (PPARs) [7]. Moreover, PPARs have also been shown to possess important anti-inflammatory properties by modulation of inflammatory signalling through the nuclear factor (NF)- $\mathrm{B}$ pathway [8]. These combined actions could make

\section{AFFILIATIONS}

Depts of * Respiratory Medicine, and \#Human Biology, NUTRIM School for Nutrition, Toxicology and Metabolism, University of Maastricht, Maastricht, the Netherlands.

CORRESPONDENCE

A.H. Remels

Dept of Respiratory Medicine University of Maastricht P0 Box 5800 6202 AZ Maastricht The Netherlands Fax: 31433875051 E-mail: a.remels@pul.unimaas.nl

Received:

June 082007

Accepted after revision:

November 042007

SUPPORT STATEMENT

A.H. Remels is supported by a grant from Numico Research. The research of H.R. Gosker is supported by an award from the Netherlands Asthma

Foundation (project number 3.2.05.038). The research of $P$. Schrauwen has been made possible by a fellowship of the Royal Netherlands Academy of Arts and Sciences and R.C. Langen is a recipient of a Veni grant from the Netherlands Organization of Scientific Research.

STATEMENT OF INTEREST None declared.

European Respiratory Journal Print ISSN 0903-1936 Online ISSN 1399-3003 
PPARs an attractive target for therapeutic intervention aimed at alleviating skeletal muscle weakness in COPD, as will be highlighted in the present article.

\section{PPARS AND COPD}

Three PPAR isoforms, $\alpha, \beta / \delta$ and $\gamma$, can be distinguished. All three exhibit tissue-specific expression, ligand-specific activation and the ability to heterodimerise with retinoid $X$ receptors, resulting in the transcription of target genes. During the past decade, PPARs have been implicated in several physiological processes, such as the regulation of lipoprotein and lipid metabolism, glucose homeostasis, the inflammatory response and cellular differentiation [9].

PPAR- $\alpha$ is expressed in many oxidative tissues, including skeletal muscle. The primary role of PPAR- $\alpha$ in skeletal muscle is regulation of fatty acid homeostasis and transcriptional control of lipid regulatory genes [10]. Additionally, PPAR- $\alpha$ is involved in the regulation of amino acid metabolism by downregulating blood and tissue branched-chain amino acid levels [11]. Other effects of PPAR- $\alpha$ activation include attenuation of inflammatory responses through inhibition of NF- $\mathrm{B}$ driven gene transcription [12]. Interestingly, secretion of inflammatory mediators in the lung decreased upon PPAR- $\alpha$ activation in a mouse model of chronic lung inflammation [13]. PPAR- $\alpha$ is activated by a number of naturally occurring, lipidderived molecules including long-chain fatty acids, eicosanoids and leukotriene $\mathrm{B}_{4}$, while the fibrate class of hypolipidaemic drugs, including fenofibrate and gemfibrozil, serve as synthetic PPAR- $\alpha$ ligand.

Although most abundant in adipose tissue, PPAR- $\gamma$ is expressed at low levels in skeletal muscle. Interestingly from a pulmonary perspective, PPAR $-\gamma$ is also expressed in the human lung. PPAR $-\gamma$ regulates the storage of fat in adipose tissue and reduces plasma glucose, lipid and insulin levels in animal models of type 2 diabetes mellitus, as well as in humans [14]. Like PPAR- $\alpha$, PPAR- $\gamma$ is involved in attenuation of the inflammatory response by reducing NF- $\kappa B$ DNA binding and repression of NF- $\kappa$ B activation through inhibition of the NF- $\kappa B$ inhibitor protein $(\mathrm{I} \kappa \mathrm{B})$ kinase complex activity $[12,15]$. Anti-inflammatory effects of PPAR- $\gamma$ activation in the lung have been shown consistently in experimental models of asthma and other airway diseases, such as COPD [16]. PPAR- $\gamma$ is the main target of the thiazolidinedione (TZD) class of insulin-sensitising drugs, which are currently a mainstay of therapy for type 2 diabetes mellitus. Besides these synthetic ligands, PPAR $-\gamma$ is activated by several naturally occurring compounds, such as prostaglandin J2 derivates and polyunsaturated fatty acids (PUFAs) [17].

PPAR- $\delta$ is a powerful regulator of fatty acid utilisation and energy homeostasis in several tissues, including the heart and skeletal muscle [7]. Consistent with such a role, PPAR- $\delta$ protein content is increased during physiological conditions characterised by elevated fatty acid utilisation, such as physical exercise or fasting. However, as PPARs are transcriptional regulators, their functionality is not only determined by abundance, but also by their activity. This may explain apparently contradictory reports showing increased PPAR- $\delta$ expression in skeletal muscle following short-term fasting versus decreased PPAR $-\delta$ expression after longer periods of fasting $[18,19]$. Therefore, selection of different time points, as well as PPAR abundance and activity measurements are necessary to clarify the actual sequence of events in skeletal muscle during metabolic adaptation. Overexpression of PPAR- $\delta$ or its activation by synthetic agonists strongly increases the lipid catabolic activities of skeletal muscle, not only by upregulating genes involved in this metabolic pathway, but also by inducing mitochondrial biogenesis and by promoting an increment of oxidative fibres [20]. PPAR- $\delta$ is characterised by the large size of its ligand-binding pocket, which allows interaction with a greater variety of activators when compared with other nuclear hormone receptors. PPAR- $\delta$ is activated by PUFAs, prostacyclin and synthetic molecules, such as phenoxyacetic acid derivates (e.g. GW 501516 and GW 0742) [17].

The current authors recently showed that PPAR- $\delta$ protein content is reduced in skeletal muscle of COPD patients compared with healthy control subjects [21]. In addition, mRNA- levels of the PPAR co-activator $1 \alpha($ PGC- $1 \alpha)$, which is a PPAR- $\gamma$ CO-activator and a master regulator of mitochondrial biogenesis, were lower in COPD patients compared with controls, and mRNA levels of PPAR- $\alpha$ were significantly lower in cachectic patients compared with noncachectic patients [21] Muscle oxidative phenotype, which is positively influenced by PPAR $-\delta$, PGC- $1 \alpha$ and PPAR- $\alpha$, is reduced in COPD [6]. This suggests that a reduced PPAR $-\delta$ and/or PPAR- $\alpha$ content or function in this disease may be involved in the observed reduction in muscular oxidative capacity that may even lead to mitochondrial dysfunction. Many pathological hallmarks of COPD have been shown to exert a negative effect on PPAR expression and activity. Hypoxia and inflammation could be responsible for lower PPAR expression levels or protein content, as there are several reports that suggest a negative influence of these parameters on PPAR levels [22-24]. Furthermore, a sedentary lifestyle, which is often adopted by COPD patients due to disease-specific limitations, can also underlie reduced levels of PPAR and PGC- $1 \alpha$ in skeletal muscle, as it has been shown that physical activity level is an important factor regulating these factors [25, 26]. Intriguingly, in other disease models, such as congestive heart failure and diabetes mellitus, both characterised by systemic inflammation and physical inactivity, a decreased oxidative capacity of skeletal muscle is also associated with a decreased expression of PGC- $1 \alpha$, PPAR- $\alpha$ and PPAR- $\delta$, mRNA suggesting a prominent role for inflammation and physical activity level in controlling PPAR and PGC-1 $\alpha$ levels [27-29]. Furthermore, it would be interesting to investigate PPAR and PGC-1 expression levels at different stages of COPD to increase insight in the aetiology and pathological mechanisms governing the observed decrease in skeletal muscle oxidative capacity in COPD patients.

\section{PPARS AND REGULATION OF SKELETAL MUSCLE FUNCTION}

\section{Inflammation}

Systemic inflammation is an important factor in the pathogenesis of weight loss and muscle wasting [30-32]. Many inflammatory responses are mediated by signalling through $\mathrm{NF}-\kappa \mathrm{B}$. In its inactive form, NF- $\kappa \mathrm{B}$ is bound to its inhibitor $\mathrm{I} \kappa \mathrm{B} \alpha$ and is located in the cytosol. After activation, NF- $\kappa B$ is released 
and translocates to the nucleus, where it initiates the transcription of its target genes, including those encoding inflammatory mediators [33]. NF- $\mathrm{KB}$ activation per se is sufficient for the induction of muscle atrophy [34]. Conversely, inhibition of NF- $\mathrm{KB}$ restored muscle mass in a number of experimental atrophy models including denervation and cancer cachexia [34]. Interestingly, NF- $\mathrm{\kappa B}$ activation has been shown in skeletal muscle of severely underweight COPD patients by decreased content of $I \kappa B \alpha$ and increased DNA binding of NF- $\kappa$ B [35]. Data regarding expression of inflammatory genes in relation to NF- $\mathrm{KB}$ activation are, however, lacking. Furthermore, some studies reported increased levels of inflammatory markers, including tumour necrosis factor (TNF)- $\alpha$ protein, in skeletal muscle of COPD patients [36, 37], while others did not [38]. This discrepancy may be related to differences in COPD phenotypes and muscles studied. Additional studies measuring inflammatory mediators in skeletal muscle of different COPD phenotypes (cachectic versus noncachectic) are needed to elucidate the exact implication of inflammatory signalling in the process of skeletal muscle wasting and cachexia in COPD.

Potent anti-inflammatory properties have been described for different PPAR isoforms. It was shown that specific PPAR- $\alpha$ activators effectively reduced NF- $\mathrm{B}$ activation and re-established control over pro-inflammatory cytokine production, such as interleukin (IL)- 6 and TNF- $\alpha$, in various mouse tissues [39]. In addition, PPAR- $\alpha$ activators were found to induce expression of $\mathrm{I} \kappa \mathrm{B} \alpha$ in primary smooth muscle cells [40]. PPAR- $\gamma$ may also play an important role in the regulation of inflammation. Several PPAR- $\gamma$ ligands have been shown to possess anti-inflammatory properties. For example, $15 \mathrm{~d}-\mathrm{PGJ}_{2}$ was shown to inhibit matrix metalloproteinase-9, IL-1 $\beta$, IL- 6 and TNF- $\alpha$ production by human monocytes/macrophages [41, 42]. The TZD troglitazone decreased plasma levels of TNF- $\alpha$ in obese human subjects and effectively reduced nuclear localisation of NF- $\kappa \mathrm{B}$ in mononuclear cells, suggesting a reduction in NF- $\kappa \mathrm{B}$ mediated transcription [43]. Besides inhibition of nuclear translocation, PPAR- $\gamma$ activation can also interfere with NF- $\mathrm{kB}$ signalling by a mechanism involving competition for transcriptional cofactors [44]. Furthermore, PPAR- $\gamma$ activation can repress NF- $\mathrm{B}$ activity by reducing NF- $\kappa \mathrm{B}$ DNA-binding activity and preventing $\mathrm{I} \kappa \mathrm{B} \alpha$ degradation [45]. Reports on anti-inflammatory effects of PPAR- $\delta$ are scarce. However, a recent study showed that PPAR- $\delta$ activation in C2C12 mouse skeletal muscle cells displayed antiinflammatory properties [46].

In summary, convincing data implicate inflammation as a trigger of cachexia, which may be modulated by systemic delivery of PPAR agonists by suppressing inflammatory and subsequent atrophy signalling in skeletal muscle (fig. 1).

\section{Oxidative stress}

Development and progression of skeletal muscle atrophy in COPD has also been associated with an imbalance between reactive oxygen species (ROS) production and antioxidant capacity $[47,48]$. Oxidative stress is present systemically as well as locally in skeletal muscle of COPD patients [49]. Experimental studies have shown that ROS can increase muscle proteolysis, inhibit muscle-specific protein expression and increase muscle cell apoptosis [50-52]. Moreover, several studies demonstrated that markers of nitrosative stress are also enhanced in skeletal muscle of COPD patients. Inducible nitric oxide synthase expression and/or nitrotyrosine formation were found to be enhanced in skeletal muscle of COPD patients in several independent studies suggesting that, in addition to oxidative stress, skeletal muscle is also exposed to nitrosative stress, which may also contribute to the process of protein degradation $[35,37,53]$. In contrast, it has been shown that nitric oxide (NO), at modest concentrations (i.e. when it appears to act as a signalling molecule causing reversible posttranslational modifications), stimulates the formation of metabolically active new mitochondria through activation of the AMPK/SIRT1/PGC- $1 \alpha /$ PPAR- $\delta$ signalling pathway [54, 55]. Based on the latter, it cannot be excluded that NO may serve to counteract mitochondrial dysfunction in conditions characterised by muscle degeneration, such as COPD, and further studies are necessary to properly address this issue.

A bulk of evidence points towards an inhibitory and attenuating effect of PPAR- $\alpha$ on oxidative stress. PPAR- $\alpha$ agonists can directly attenuate oxidative stress by preventing ROS generation, as it was shown that PPAR- $\alpha$ activation in mice restored impaired cellular redox balance, evidenced by a lowering of tissue lipid peroxidation and elimination of constitutively active NF- $\kappa$ B [39]. Furthermore, PPAR- $\alpha$ activation by fish oil feeding and fenofibrate administration to mice downregulated hydroxysteroid markers of ROS production in the liver [56]. Several studies demonstrated that activation of PPAR- $\alpha$ in vivo also causes an upregulation in a number of antioxidant enzymes, including catalase, copper(II) and zinc(II) superoxide dismutase (SOD) and mediators of the glutathione

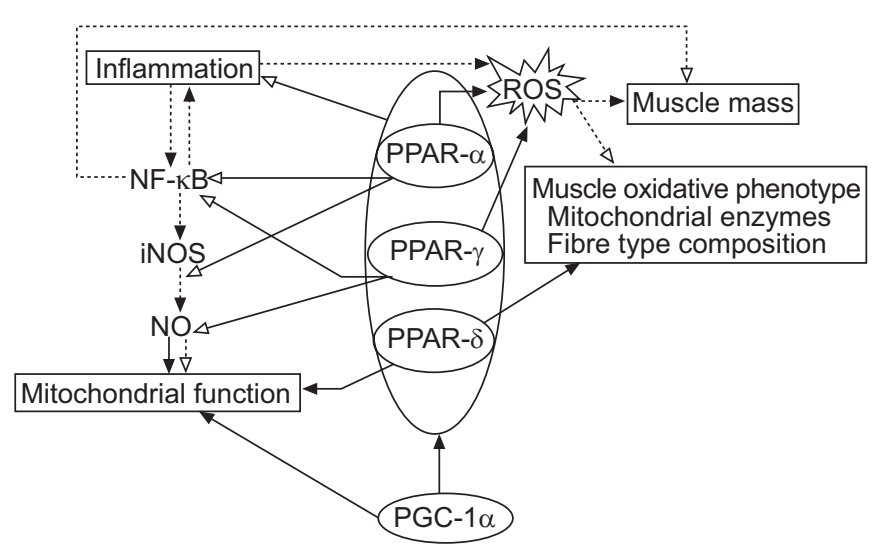

FIGURE 1. Negative effects of inflammation, and oxidative and nitrosative stress on muscle mass and oxidative phenotype, and the different levels of modulation by peroxisome proliferator-activated receptors (PPARs). Inflammation, oxidative and nitrosative stress negatively affect muscle mass and oxidative capacity. Different PPAR subtypes inhibit inflammatory signalling and oxidative and nitrosative stress at the indicated levels and may prevent or restore loss of muscle mass and oxidative phenotype. In addition, PPAR- $\delta$ and PPAR- $\gamma$ co-activator- $1 \alpha$ (PGC-1 $\alpha$ ) positively modulate muscle mass and oxidative phenotype and may oppose the effects of inflammation and oxidative-nitrosative stress. NF-кB: nuclear factor-кB; iNOS: inducible nitric oxide synthase; NO: nitric oxide; ROS: reactive oxygen species. $\cdots \cdots \cdots \cdot \cdots \cdot$ negative effect on muscle mass and/or muscle oxidative phenotype; —- positive effect on muscle mass and/or muscle oxidative phenotype; open arrowheads: inhibitory signal; filled arrowheads: stimulatory signal. 
pathway [57]. More recent research confirms previous reports that PPAR- $\alpha$ activation in rats increases the antioxidant capacity and thereby modulates the oxidant-antioxidant balance in favour of the latter $[58,59]$. In addition, cardiac-specific PPAR$\alpha$ deficiency was accompanied by a decrease in cardiac manganese SOD expression and activity, and a subsequent increase in oxidative/nitrosative damage [60]. Besides PPAR- $\alpha$ agonists, PPAR- $\gamma$ agonists are also able to reduce ROS formation $[61,62]$. Two different PPAR- $\gamma$ ligands were found to increase catalase mRNA expression and activity in endothelial cells [63]. Furthermore, glutathione and ascorbic acid levels in the hearts of diabetic rabbits were increased after PPAR- $\gamma$ activation when compared with diabetic nontreated animals [64]. The exact mechanisms involved in the reduction of oxidative stress by PPAR $-\alpha$ and PPAR $-\gamma$ agonists remain elusive.

Oxidative stress has been demonstrated consistently in skeletal muscle of COPD patients [53]. As PPAR activation diminishes oxidative stress in multiple tissues, it is reasonable to expect similar effects in skeletal muscle, which may be beneficial in alleviating skeletal muscle dysfunction in COPD.

\section{Oxidative metabolism}

A decrease in the type I slow oxidative muscle fibres and a concomitant increase in type II fast-twitch glycolytic fibres is reported in peripheral skeletal muscles of COPD patients, indicative of a relative shift from oxidative to glycolytic capacity [65]. As type II muscle fibres have a lower resistance to fatigue, this fibre-type shift may result in reduced endurance, as observed in peripheral skeletal muscle of COPD patients. According to this fibre-type shift, analyses of enzyme activities also reveal an overall increase in glycolytic and decrease in oxidative activities in peripheral skeletal muscles of these patients affecting muscle substrate metabolism $[6,66]$.

Expression of muscle genes that promote selective utilisation of lipid substrates is augmented during physiological states that are associated with increased systemic delivery of free fatty acids, such as exercise. Interestingly, many of the same muscle genes are also upregulated by in vivo administration of PPAR- $\alpha$ activators. It is observed that PPAR- $\alpha$ protein content is increased by exercise training and induced during myocyte differentiation, two conditions characterised by an increase in oxidative capacity $[67,68]$. In addition, PPAR- $\alpha$ regulates fatty acid utilisation and expression of several genes involved in fatty acid $\beta$-oxidation in primary human skeletal muscle cells. [69]. Skeletal muscle expresses high levels of PPAR- $\delta$ and activation of the $\delta$-subtype increases fatty acid $\beta$-oxidation, as well as mRNA levels of several classical PPAR- $\alpha$ target genes in both rodent and human skeletal muscle cells [70]. Overexpression of PPAR- $\delta$ in $\mathrm{C} 2 \mathrm{C} 12$ myotubes resulted in an increment in fatty acid oxidation after activation by a synthetic ligand [71, 72]. In addition, analysis of rat myotubes treated with the PPAR- $\delta$ subtype selective agonist, GW 501516, revealed that PPAR- $\delta$ controls fatty acid oxidation by regulating genes involved in fatty acid transport, $\beta$-oxidation and mitochondrial respiration $[73,74]$. These results, showing a significant overlap in the functions of PPAR $-\alpha$ and $-\delta$, indicate that both subtypes play an important role in mediating lipidinduced regulation of oxidative pathways.
A recent study examining mice overexpressing PPAR- $\delta$ in muscle showed that the number of succinate dehydrogenase (SDH)-positive fibres (as a measure for oxidative fibres) was considerably increased in various muscles. This remodelling was due to hyperplasia and/or conversion of SDH-negative to -positive fibres, similar to what is observed upon endurance training [71, 75]. These histological observations were confirmed by the finding that muscle-specific PPAR- $\delta$ overexpression led to an increase of other oxidative enzymes, such as citrate synthase and $\beta$-hydroxyacyl-coenzyme A dehydrogenase. In addition, mitochondrial biogenesis was also enhanced. Conversely, activities of glycolytic enzymes remained unchanged [75]. Conversion of glycolytic fibres to oxidative fibres has also been reported in genetically altered animals that overexpress PGC- $1 \alpha$, which is a PPAR coactivator and a master regulator of mitochondrial biogenesis. Notably, putative type II muscles from PGC- $1 \alpha$ transgenic mice also express proteins characteristic of type I fibres, such as troponin I (slow) and myoglobin, and show a greater resistance to fatigue. These data indicate that, in addition to PPAR- $\delta$, PGC- $1 \alpha$ is also a principal factor regulating muscle fibre-type determination and skeletal muscle exercise capacity [76].

Given the strong involvement of the PPARs and PGC- $1 \alpha$ in regulation of skeletal muscle oxidative phenotype, the fact that skeletal muscle oxidative phenotype is impaired in COPD and the observation of reduced PPAR expression levels in skeletal muscle of COPD patients, it is tempting to suggest a possible therapeutic role for PPAR activators in muscle metabolism in COPD.

\section{HOW CAN PPAR ACTIVITY BE MODULATED IN COPD?}

COPD management requires an integrated approach aimed at pulmonary and extrapulmonary manifestations. In addition to therapies aimed at alleviating the primary lung impairment, evidence is accumulating that therapies targeting skeletal muscle dysfunction have a significant positive effect on quality of life and may even improve survival. Experimental studies have shown that PPAR- $\alpha$ and PPAR $-\gamma$ can exert anti-inflammatory effects in the pulmonary compartment, which, with additional research, may translate into an interesting therapeutic avenue in the context of COPD lung pathology [13, 66, 67]. Moreover, based on the evidence described in the present article, it is tempting to suggest that a reduced content and activity of the PPARs may underlie some of the muscular disturbances in COPD. Nutritional intervention and exercise may positively influence PPAR content and activity in skeletal muscle. Indirect support for this notion is the beneficial effect of pulmonary rehabilitation on mitochondrial (fat) oxidative capacity and hence on skeletal muscle function in skeletal muscle of COPD patients [77]. PUFAs are common components of fatty fish and olive oil and are known PPAR activators. Interestingly, a recent randomised clinical trial showed that nutritional supplementation with PUFAs as adjunct to exercise training in COPD patients markedly enhanced exercise capacity compared with the placebo-treated group [78]. Several aspects of intervention with PPAR activators must be kept in mind. Two different aspects must be kept in mind. First, the positive influence of PPAR activators on skeletal muscle oxidative capacity and, secondly, the potent anti-inflammatory capacities of these agents. Concerning the effects on muscle oxidative capacity, the 
rationale would be to introduce PPAR activators clinically to patients for whom daily life activities are limited by the decreased oxidative capacity of their lower limb skeletal muscles. Conversely, PPAR activators can be used to alleviate inflammatory status of COPD patients, for example, after exacerbations or in late-stage COPD to ameliorate the systemic inflammatory process. In addition, it is conceivable that PPAR agonists can delay or inhibit disease-specific processes, such as inflammation, if applied at early stages of disease development.

In conclusion, single or combined peroxisome proliferatoractivated receptor agonists may represent a novel class of pharmacological agents that could be helpful in the management of chronic obstructive pulmonary disease.

\section{REFERENCES}

1 Rabe KF, Hurd S, Anzueto A, et al. Global Strategy for the Diagnosis, Management, and Prevention of COPD - 2006 Update. Am J Respir Crit Care Med 2007; 176: 532-555.

2 Balasubramanian VP, Varkey B. Chronic obstructive pulmonary disease: effects beyond the lungs. Curr Opin Pulm Med 2006; 12: 106-112.

3 Agusti AG. Systemic effects of chronic obstructive pulmonary disease. Proc Am Thorac Soc 2005; 2: 367-372.

4 Mador MJ. Muscle mass, not body weight, predicts outcome in patients with chronic obstructive pulmonary disease. Am J Respir Crit Care Med 2002; 166: 787-789.

5 Gosker H, Zeegers M, Wouters E, Schols AM. Muscle fibre type shifting in the vastus lateralis of patients with COPD is associated with disease severity: a systematic review and meta-analysis. Thorax 2007; 62: 944-949..

6 Gosker HR, Kubat B, Schaart G, van der Vusse GJ, Wouters EF, Schols AM. Myopathological features in skeletal muscle of patients with chronic obstructive pulmonary disease. Eur Respir J 2003; 22: 280-285.

7 Luquet S, Gaudel C, Holst D, et al. Roles of PPAR $\delta$ in lipid absorption and metabolism: a new target for the treatment of type 2 diabetes. Biochim Biophys Acta 2005; 1740: 313-317.

8 Becker J, Delayre-Orthez C, Frossard N, Pons F. Regulation of inflammation by PPARs: a future approach to treat lung inflammatory diseases? Fundam Clin Pharmacol 2006; 20: 429-447.

9 Blanquart C, Barbier O, Fruchart JC, Staels B, Glineur C. Peroxisome proliferator-activated receptors: regulation of transcriptional activities and roles in inflammation. $J$ Steroid Biochem Mol Biol 2003; 85: 267-273.

10 Muoio DM, MacLean PS, Lang DB, et al. Fatty acid homeostasis and induction of lipid regulatory genes in skeletal muscles of peroxisome proliferator-activated receptor (PPAR) alpha knock-out mice. Evidence for compensatory regulation by PPAR delta. J Biol Chem 2002; 277: 26089-26097.

11 Harris RA, Joshi M, Jeoung NH. Mechanisms responsible for regulation of branched-chain amino acid catabolism. Biochem Biophys Res Commun 2004; 313: 391-396.

12 Kersten S, Desvergne B, Wahli W. Roles of PPARs in health and disease. Nature 2000; 405: 421-424.

13 Delayre-Orthez C, Becker J, Guenon I, et al. PPAR $\alpha$ downregulates airway inflammation induced by lipopolysaccharide in the mouse. Respir Res 2005; 6: 91.
14 Rieusset J, Touri F, Michalik L, et al. A new selective peroxisome proliferator-activated receptor $\gamma$ antagonist with antiobesity and antidiabetic activity. Mol Endocrinol 2002; 16: 2628-2644.

15 Verges B. Clinical interest of PPARs ligands. Diabetes Metab 2004; 30: 7-12.

16 Spears M, McSharry C, Thomson NC. Peroxisome proliferator-activated receptor-gamma agonists as potential anti-inflammatory agents in asthma and chronic obstructive pulmonary disease. Clin Exp Allergy 2006; 36: 1494-1504.

17 Akiyama TE, Meinke PT, Berger JP. PPAR ligands: potential therapies for metabolic syndrome. Curr Diab Rep 2005; 5: 45-52.

18 Luquet S, Lopez-Soriano J, Holst D, et al. Roles of peroxisome proliferator-activated receptor delta (PPAR $\delta$ ) in the control of fatty acid catabolism. A new target for the treatment of metabolic syndrome. Biochimie 2004; 86: 833-837.

19 de Lange P, Ragni M, Silvestri E, et al. Combined cDNA array/RT-PCR analysis of gene expression profile in rat gastrocnemius muscle: relation to its adaptive function in energy metabolism during fasting. FASEB J 2004; 18: 350-352.

20 Fredenrich A, Grimaldi PA. Roles of peroxisome proliferator-activated receptor $\delta$ in skeletal muscle function and adaptation. Curr Opin Clin Nutr Metab Care 2004; 7: 377-381.

21 Remels AH, Schrauwen P, Broekhuizen R, et al. Expression and content of PPARs is reduced in skeletal muscle of COPD patients. Eur Respir J 2007; 30: 245-252.

22 Narravula S, Colgan SP. Hypoxia-inducible factor 1mediated inhibition of peroxisome proliferator-activated receptor $\alpha$ expression during hypoxia. J Immunol 2001; 166 : 7543-7548.

23 Sung CK, She H, Xiong S, Tsukamoto H. Tumor necrosis factor- $\alpha$ inhibits peroxisome proliferator-activated receptor $\gamma$ activity at a posttranslational level in hepatic stellate cells. Am J Physiol Gastrointest Liver Physiol 2004; 286: G722-G729.

24 Tham DM, Martin-McNulty B, Wang YX, et al. Angiotensin II is associated with activation of NF- $\kappa$ B-mediated genes and downregulation of PPARs. Physiol Genomics 2002; 11: 21-30.

25 Fritz T, Kramer DK, Karlsson HK, et al. Low-intensity exercise increases skeletal muscle protein expression of PPAR $\delta$ and UCP3 in type 2 diabetic patients. Diabetes Metab Res Rev 2006; 22: 492-498.

26 Sandri M, Lin J, Handschin C, et al. PGC- $1 \alpha$ protects skeletal muscle from atrophy by suppressing FoxO3 action and atrophy-specific gene transcription. Proc Natl Acad Sci USA 2006; 103: 16260-16265.

27 Garnier A, Fortin D, Delomenie C, Momken I, Veksler V, Ventura-Clapier R. Depressed mitochondrial transcription factors and oxidative capacity in rat failing cardiac and skeletal muscles. J Physiol 2003; 551: 491-501.

28 Roden M. Muscle triglycerides and mitochondrial function: possible mechanisms for the development of type 2 diabetes. Int J Obes (Lond) 2005; 29: Suppl. 2, S111-S115.

29 Carey AL, Petersen EW, Bruce CR, et al. Discordant gene expression in skeletal muscle and adipose tissue of patients with type 2 diabetes: effect of interleukin-6 infusion. Diabetologia 2006; 49: 1000-1007. 
30 Guttridge DC, Mayo MW, Madrid LV, Wang CY, Baldwin AS Jr. NF- $\mathrm{kB}$-induced loss of MyoD messenger RNA: possible role in muscle decay and cachexia. Science 2000; 289: 2363-2366.

31 Langen RC, Schols AM, Kelders MC, Wouters EF, JanssenHeininger YM. Inflammatory cytokines inhibit myogenic differentiation through activation of nuclear factor- $\kappa \mathrm{B}$. FASEB J 2001; 15: 1169-1180.

32 Langen RC, Schols AM, Kelders MC, van der Velden JL, Wouters EF, Janssen-Heininger YM. Muscle wasting and impaired muscle regeneration in a murine model of chronic pulmonary inflammation. Am J Respir Cell Mol Biol 2006; 35: 689-696.

33 Xiao C, Ghosh S. NF- $\kappa$ B, an evolutionarily conserved mediator of immune and inflammatory responses. Adv Exp Med Biol 2005; 560: 41-45.

34 Cai D, Frantz JD, Tawa NE Jr, et al. IKK $\beta / \mathrm{NF}-\kappa \mathrm{B}$ activation causes severe muscle wasting in mice. Cell 2004; 119: 285-298.

35 Agusti A, Morla M, Sauleda J, Saus C, Busquets X. NF-кB activation and iNOS upregulation in skeletal muscle of patients with COPD and low body weight. Thorax 2004; 59: 483-487.

36 Rabinovich RA, Bastos R, Ardite E, et al. Mitochondrial dysfunction in COPD patients with low body mass index. Eur Respir J 2007; 29: 643-650.

37 Montes de Oca M, Torres SH, De Sanctis J, Mata A, Hernandez N, Talamo C. Skeletal muscle inflammation and nitric oxide in patients with COPD. Eur Respir J 2005; 26: 390-397.

38 Barreiro E, Schols A.M, Polkey M, Galdiz J, et al. Cytokine profile in quadriceps muscle of patients with severe chronic obstructive pulmonary disease. Thorax 2007; [Epub ahead of print PMID: 17815568].

39 Poynter ME, Daynes RA. Peroxisome proliferator-activated receptor $\alpha$ activation modulates cellular redox status, represses nuclear factor- $\mathrm{\kappa} \mathrm{B}$ signaling, and reduces inflammatory cytokine production in aging. J Biol Chem 1998; 273: 32833-32841.

40 Staels B, Koenig W, Habib A, et al. Activation of human aortic smooth-muscle cells is inhibited by PPAR $\alpha$ but not by PPAR $\gamma$ activators. Nature 1998; 393: 790-793.

41 Jiang C, Ting AT, Seed B. PPAR- $\gamma$ agonists inhibit production of monocyte inflammatory cytokines. Nature 1998; 391: 82-86.

42 Chawla A, Barak Y, Nagy L, Liao D, Tontonoz P, Evans RM. PPAR- $\gamma$ dependent and independent effects on macrophage-gene expression in lipid metabolism and inflammation. Nat Med 2001; 7: 48-52.

43 Dandona P, Aljada A. A rational approach to pathogenesis and treatment of type 2 diabetes mellitus, insulin resistance, inflammation, and atherosclerosis. Am J Cardiol 2002; 90: 27G-33G.

44 Li M, Pascual G, Glass CK. Peroxisome proliferatoractivated receptor $\gamma$-dependent repression of the inducible nitric oxide synthase gene. Mol Cell Biol 2000; 20: 4699-4707.

45 Castrillo A, Diaz-Guerra MJ, Hortelano S, Martin-Sanz P,

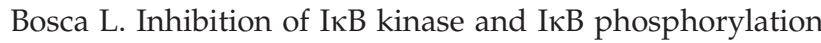
by 15 -deoxy- $\delta(12,14)$-prostaglandin $\mathrm{J}(2)$ in activated murine macrophages. Mol Cell Biol 2000; 20: 1692-1698.
46 Woo $\mathrm{CH}$, Massett MP, Shishido T, et al. ERK5 activation inhibits inflammatory responses via peroxisome proliferatoractivated receptor delta (PPARS) stimulation. J Biol Chem 2006; 281: 32164-32174.

47 MacNee W. Oxidants/antioxidants and COPD. Chest 2000; 117: Suppl. 5, 303S-317S.

48 Koechlin C, Couillard A, Cristol JP, et al. Does systemic inflammation trigger local exercise-induced oxidative stress in COPD? Eur Respir J 2004; 23: 538-544.

49 MacNee W. Oxidants and COPD. Curr Drug Targets Inflamm Allergy 2005; 4: 627-641.

50 Langen RC, Schols AM, Kelders MC, et al. Tumor necrosis factor- $\alpha$ inhibits myogenesis through redox-dependent and -independent pathways. Am J Physiol Cell Physiol 2002; 283: C714-C721.

51 Buck M, Chojkier M. Muscle wasting and dedifferentiation induced by oxidative stress in a murine model of cachexia is prevented by inhibitors of nitric oxide synthesis and antioxidants. EMBO J 1996; 15: 1753-1765.

52 Stangel M, Zettl UK, Mix E, et al. $\mathrm{H}_{2} \mathrm{O}_{2}$ and nitric oxidemediated oxidative stress induce apoptosis in rat skeletal muscle myoblasts. J Neuropathol Exp Neurol 1996; 55: 36-43.

53 Barreiro E, Gea J, Corominas JM, Hussain SN. Nitric oxide synthases and protein oxidation in the quadriceps femoris of patients with chronic obstructive pulmonary disease. Am J Respir Cell Mol Biol 2003; 29: 771-778.

54 Jobgen WS, Fried SK, Fu WJ, Meininger CJ, Wu G. Regulatory role for the arginine-nitric oxide pathway in metabolism of energy substrates. J Nutr Biochem 2006; 17: 571-588.

55 Nisoli E, Clementi E, Paolucci C, et al. Mitochondrial biogenesis in mammals: the role of endogenous nitric oxide. Science 2003; 299: 896-899.

56 Takahashi M, Tsuboyama-Kasaoka N, Nakatani T, et al. Fish oil feeding alters liver gene expressions to defend against PPAR $\alpha$ activation and ROS production. Am J Physiol Gastrointest Liver Physiol 2002; 282: G338-G348.

57 Toyama T, Nakamura H, Harano Y, et al. PPAR $\alpha$ ligands activate antioxidant enzymes and suppress hepatic fibrosis in rats. Biochem Biophys Res Commun 2004; 324: 697-704.

58 Beltowski J, Wojcicka G, Mydlarczyk M, Jamroz A. The effect of peroxisome proliferator-activated receptors alpha $(\mathrm{PPAR} \alpha)$ agonist, fenofibrate, on lipid peroxidation, total antioxidant capacity, and plasma paraoxonase 1 (PON 1) activity. J Physiol Pharmacol 2002; 53: 463-475.

59 Inoue I, Noji S, Awata $\mathrm{T}$, et al. Bezafibrate has an antioxidant effect: peroxisome proliferator-activated receptor $\alpha$ is associated with $\mathrm{Cu}^{2+}, \mathrm{Zn}^{2+}$-superoxide dismutase in the liver. Life Sci 1998; 63: 135-144.

60 Schulz R, Ali MA. PPAR $\alpha$ : essential component to prevent myocardial oxidative stress? Am J Physiol Heart Circ Physiol 2007; 293: H11-H12.

61 Tao L, Liu HR, Gao E, et al. Antioxidative, antinitrative, and vasculoprotective effects of a peroxisome proliferatoractivated receptor- $\gamma$ agonist in hypercholesterolemia. Circulation 2003; 108: 2805-2811.

62 Shiojiri T, Wada K, Nakajima A, et al. PPAR $\gamma$ ligands inhibit nitrotyrosine formation and inflammatory mediator expressions in adjuvant-induced rheumatoid arthritis mice. Eur J Pharmacol 2002; 448: 231-238. 
63 Girnun GD, Domann FE, Moore SA, Robbins ME. Identification of a functional peroxisome proliferatoractivated receptor response element in the rat catalase promoter. Mol Endocrinol 2002; 16: 2793-2801.

64 Delerive P, Fruchart JC, Staels B. Peroxisome proliferatoractivated receptors in inflammation control. J Endocrinol 2001; 169: 453-459.

65 Satta A, Migliori GB, Spanevello A, et al. Fibre types in skeletal muscles of chronic obstructive pulmonary disease patients related to respiratory function and exercise tolerance. Eur Respir J 1997; 10: 2853-2860.

66 Maltais F, LeBlanc P, Simard C, et al. Skeletal muscle adaptation to endurance training in patients with chronic obstructive pulmonary disease. Am J Respir Crit Care Med 1996; 154: 442-447.

67 Cresci S, Wright LD, Spratt JA, Briggs FN, Kelly DP. Activation of a novel metabolic gene regulatory pathway by chronic stimulation of skeletal muscle. Am J Physiol 1996; 270: C1413-C1420.

68 Horowitz JF, Leone TC, Feng W, Kelly DP, Klein S. Effect of endurance training on lipid metabolism in women: a potential role for PPAR $\alpha$ in the metabolic response to training. Am J Physiol Endocrinol Metab 2000; 279: E348-E355.

69 Baldan A, Relat J, Marrero PF, Haro D. Functional interaction between peroxisome proliferator-activated receptors-alpha and Mef-2C on human carnitine palmitoyltransferase 1beta (CPT1beta) gene activation. Nucleic Acids Res 2004; 32: 4742-4749.

70 Leone TC, Weinheimer CJ, Kelly DP. A critical role for the peroxisome proliferator-activated receptor alpha (PPAR $\alpha$ ) in the cellular fasting response: the PPARalpha-null mouse as a model of fatty acid oxidation disorders. Proc Natl Acad Sci USA 1999; 96: 7473-7478.

71 Grimaldi PA. Roles of PPAR $\delta$ in the control of muscle development and metabolism. Biochem Soc Trans 2003; 31: 1130-1132.

72 Holst D, Luquet S, Nogueira V, Kristiansen K, Leverve X, Grimaldi PA. Nutritional regulation and role of peroxisome proliferator-activated receptor delta in fatty acid catabolism in skeletal muscle. Biochim Biophys Acta 2003; 1633: 43-50.

73 Tanaka T, Yamamoto J, Iwasaki S, et al. Activation of peroxisome proliferator-activated receptor delta induces fatty acid beta-oxidation in skeletal muscle and attenuates metabolic syndrome. Proc Natl Acad Sci USA 2003; 100: 15924-15929.

74 Wang YX, Lee CH, Tiep S, et al. Peroxisome-proliferatoractivated receptor delta activates fat metabolism to prevent obesity. Cell 2003; 113: 159-170.

75 Luquet S, Lopez-Soriano J, Holst D, et al. Peroxisome proliferator-activated receptor delta controls muscle development and oxidative capability. FASEB J 2003; 17: 2299-2301.

76 Lin $\mathrm{J}, \mathrm{Wu} \mathrm{H}$, Tarr PT, et al. Transcriptional co-activator PGC-1 alpha drives the formation of slow-twitch muscle fibres. Nature 2002; 418: 797-801.

77 Doherty DE, Briggs DD Jr. Long-term nonpharmacologic management of patients with chronic obstructive pulmonary disease. Clin Cornerstone, 2004: Suppl. 2, S29-S34.

78 Broekhuizen R, Wouters EF, Creutzberg EC, WelingScheepers CA, Schols AM. Polyunsaturated fatty acids improve exercise capacity in chronic obstructive pulmonary disease. Thorax 2005; 60: 376-382. 